\title{
Different Fetal and Neonatal Growth between Early- and Late-Onset Preeclampsia
}

\author{
Takashi Mitsui, Hisashi Masuyama, Eriko Eto, Etsuko Nobumoto, Kei Hayata, \\ Yuji Hiramatsu \\ Department of Obstetrics and Gynecology, Okayama University Graduate School of Medicine, \\ Dentistry and Pharmaceutical Sciences, Okayama, Japan \\ Email: masuyama@cc.okayama-u.ac.jp
}

Received 24 July 2015; accepted 25 August 2015; published 28 August 2015

Copyright (C) 2015 by authors and Scientific Research Publishing Inc.

This work is licensed under the Creative Commons Attribution International License (CC BY). http://creativecommons.org/licenses/by/4.0/

(c) (i)

\section{Abstract}

Preeclampsia is a heterogeneous disease, and there are major differences in severity, fetal growth and poor placentation between early- and late-onset preeclampsia. Here, we examined the effect of onset period on fetal and neonatal growth in preeclampsia with a cross-sectional study including 102 pregnant women with preeclampsia visited Okayama University Hospital from 2009 to 2013. The subjects were retrospectively compared in terms of body mass index (BMI), weight gain during pregnancy, complications, weeks of delivery, neonatal body weight and BMI at birth, fetal growth restriction (FGR), small for gestational age (SGA), pathological findings in the placenta, and infant's weight at 1 month after birth. Neonatal body weight and BMI at birth were significantly lower and the extent of FGR and the frequency of SGA were higher in early-onset group compared with late-onset group. Mean daily weight gain during the neonatal period was significantly lower in the early-onset group compared with the late-onset group, however the weight gain rate during the neonatal period in the early-onset group was higher than that in late-onset group. In conclusions, there are significant differences in fetal and neonatal growth between early- and late-onset preeclampsia and the catch up for growth might start during neonatal period.

\section{Keywords}

Body Mass Index, Fetal Growth Restriction, Onset Period, Preeclampsia

\section{Introduction}

Preeclampsia (PE) is defined as hypertension occurring between 20 weeks of gestation and 12 weeks post-par-

How to cite this paper: Mitsui, T., Masuyama, H., Eto, E., Nobumoto, E., Hayata, K. and Hiramatsu, Y. (2015) Different Fetal and Neonatal Growth between Early- and Late-Onset Preeclampsia. Open Journal of Obstetrics and Gynecology, 5, 516-521. http://dx.doi.org/10.4236/ojog.2015.59074 
stum. Alternatively, PE is defined as hypertension accompanied by proteinuria, and it does not incidentally occur in combination with pregnancy [1] [2]. PE occurs in 3\% - 5\% of all pregnancies and results in substantial maternal and neonatal morbidity and mortality [3]. PE is thought to be a heterogeneous disease, and there are major differences in severity, fetal growth, poor placentation, and pulsed Doppler findings between early- and late-onset PE [3]-[5]. These findings suggest that there may be two different entities to consider when investigating the pathophysiology of PE. Actually, we have demonstrated that early-onset PE is mainly caused by changes to factors in the placenta by placental hypoplasia, while late-onset PE might be caused by too much of a burden on the pregnant woman's body with obesity or metabolic syndrome [6] [7].

In this study, we examined the perinatal characteristics between early- and late-onset preeclampsia in PE. This study aimed to investigate the effect of onset period on fetal and neonatal growth under two possible conditions (i.e., placental factors and maternal metabolic conditions) that might affect the strategy for the management of PE.

\section{Materials and Methods}

A total of 102 pregnant women with PE who visited Okayama University Hospital, Department of Obstetrics and Gynecology (Okayama, Japan) from 2009 to 2013 were included in the present study. According to the definition of PE by the Japan Society of Obstetrics and Gynecology [8], mild PE was defined as patients with persistent blood pressure elevation to a systolic level of $140 \mathrm{mmHg}$ or a diastolic level of $90 \mathrm{mmHg}$ on two occasions, several hours apart, with or without proteinuria of $>300 \mathrm{mg}$ in a 24-h urine collection. Severe PE was defined as either severe hypertension (systolic blood pressure $>160 \mathrm{mmHg}$ or diastolic blood pressure $>110 \mathrm{mmHg}$ ) or severe proteinuria ( $>2.0 \mathrm{~g}$ of protein collected in a 24-h urine sample). Because this study's subject was Japanese, the definition of PE by the Japan Society of Obstetrics and Gynecology was used.

The subjects were divided into two groups: the early-onset group was diagnosed before 32 gestational weeks and the late-onset group was diagnosed at 32 gestational weeks or later according to the definition of the Japan Society of Obstetrics and Gynecology [8]. The two groups were retrospectively compared in terms of age, medical history, history of pregnancy, family history, body mass index (BMI; body mass index was defined as the weight in kilograms divided by the square of the height in meters) before becoming pregnant, weight gain during pregnancy, weeks at delivery, neonatal body weight at birth, neonatal height at birth, neonatal BMI at birth, extent of fetal growth restriction (FGR; fetal growth restriction was a fetal weight that is below the -1.5 SD for the standard deviation of estimated weight from Japanese standard fetal weight. [9]), whether the infant was small-for-gestational age (SGA; small-for-gestational age was body weights at birth $<10$ th centile for babies of the same gestational age [10]-[13]), infant's body weight at 1 month after birth, and pathological findings in the placenta. Pathological findings in the placenta were vasculopathy, embolism, distal villous hypoplasia, or other pathological findings consistent with preeclampsia [14].

This study was approved by the Institutional Ethical Review Board of Okayama University Graduate School of Medicine, Dentistry and Pharmaceutical Sciences and all subjects gave their informed consent. The statistical methods that were used included the Student's t-test and the $\chi^{2}$ test. A p $<0.05$ was defined as significant. SPSS Statistics version 20 (IBM Co., New York, USA) was used to perform the statistical analysis.

\section{Results}

The 102 patients of PE included 27 (26.5\%) early-onset patients and 75 (73.5\%) late-onset patients. The 63 (61.8\%) patients were diagnosed with severe PE. The mean number of weeks at delivery was 37.1 weeks, and 53 of the 102 (52.0\%) patients had cesarean delivery. The mean neonatal body weight at birth was $2444.7 \mathrm{~g}$, neonatal BMI at birth was $10.9 \mathrm{~kg} / \mathrm{m}^{2}$, the extent of FGR was $-0.9 \mathrm{SD}$, and the frequency of SGA was 32 (31.4\%) of 102 patients. With regard to placenta pathology, 47 patients were subjected to histological diagnosis after delivery, of which 31 (65.9\%) showed vascular wall thickening or thrombus formation. Maternal, perinatal and neonatal characteristics are shown in Table 1.

For comparing maternal characteristics and fetal growth in the early-onset and late-onset groups (Table 2), the rate of primigravida $(\mathrm{p}=0.04)$ in the late-onset group was significantly higher than that in the early-onset group. No significant differences were observed in maternal age, body weight, and BMI before pregnancy, weight at delivery, and weight gain during pregnancy. The extent of FGR in early-onset group was significantly higher compared with that in the late-onset group $(\mathrm{p}=0.03)$. 
Table 1. Maternal, neonatal, and placental characteristics.

\begin{tabular}{|c|c|c|c|}
\hline \multirow{2}{*}{$\begin{array}{l}\text { Maternal characteristics }(\mathrm{n}=102) \\
\text { Age (years)* }\end{array}$} & & \multicolumn{2}{|c|}{ Neonatal characteristics $(\mathrm{n}=102)$} \\
\hline & $33.8 \pm 5.7$ & Body weight (g)* & $2444.7 \pm 773.1$ \\
\hline Times of pregnancy (time)* & $0.5 \pm 0.9$ & Height $(\mathrm{cm})^{*}$ & $46.7 \pm 4.6$ \\
\hline Body weight $(\mathrm{kg})^{*}$ & $61.2 \pm 16.1$ & $\mathrm{BMI}\left(\mathrm{kg} / \mathrm{cm}^{2}\right)^{*}$ & $10.9 \pm 1.7$ \\
\hline $\operatorname{BMI}\left(\mathrm{kg} / \mathrm{m}^{2}\right)^{*}$ & $24.7 \pm 5.8$ & Apgar score $1 \mathrm{~min} *$ & $7.3 \pm 2.0$ \\
\hline Body weight at delivery (kg)* & $68.4 \pm 15.0$ & Apgar score 5 min* & $8.5 \pm 1.4$ \\
\hline Body weight gain $(\mathrm{kg})^{*}$ & $7.3 \pm 5.0$ & FGR (SD)* & $-0.9 \pm 1.6$ \\
\hline Type & & SGA & $32(31.4 \%)$ \\
\hline Early onset & $27(26.5 \%)$ & \multicolumn{2}{|c|}{ Characteristics in placenta $(n=47)$} \\
\hline Late onset & 75 (73.5\%) & Weight (g)* & $506.6 \pm 153.7$ \\
\hline Weeks of delivery (week)* & $37.1 \pm 2.9$ & Size $\left(\mathrm{cm}^{2}\right)^{*}$ & $294.4 \pm 91.3$ \\
\hline Severity & & \multicolumn{2}{|c|}{ Abnormal Pathological finding } \\
\hline $\mathrm{H}$ & $21(20.6 \%)$ & & $31(65.9 \%)$ \\
\hline $\mathrm{Ph}$ & $15(14.7 \%)$ & & \\
\hline $\mathrm{Ph}$ & $3(2.9 \%)$ & & \\
\hline $\mathrm{H}$ & $17(16.7 \%)$ & & \\
\hline $\mathrm{Ph}$ & $35(34.3 \%)$ & & \\
\hline $\mathrm{PH}$ & $11(10.8 \%)$ & & \\
\hline \multicolumn{4}{|l|}{ Methods of delivery } \\
\hline Vaginal delivery & $49(48.0 \%)$ & & \\
\hline Caesarean section & 53 (52.0\%) & & \\
\hline
\end{tabular}

*Data are average $( \pm \mathrm{SD})$.

Table 2. Comparison of maternal characteristics and fetal growth between early- and late-onset preeclampsia.

\begin{tabular}{|c|c|c|c|}
\hline Variables & Early onset (n = 27) & Late onset $(\mathrm{n}=75)$ & $\mathrm{p}$ value \\
\hline Age (years)* & $33.9 \pm 6.0$ & $33.8 \pm 5.7$ & 0.49 \\
\hline \multicolumn{4}{|l|}{ Gravidity } \\
\hline Primigravida & $14(51.9 \%)$ & $53(70.7 \%)$ & 0.04 \\
\hline Multigravida & $13(48.1 \%)$ & $22(29.3 \%)$ & 0.01 \\
\hline Body Weight (kg)* & $62.4 \pm 16.2$ & $60.9 \pm 16.1$ & 0.34 \\
\hline BMI $\left(\mathrm{kg} / \mathrm{m}^{2}\right)^{*}$ & $25.0 \pm 5.9$ & $24.4 \pm 5.8$ & 0.34 \\
\hline Body weight at delivery (kg)* & $69.9 \pm 14.7$ & $67.9 \pm 15.1$ & 0.27 \\
\hline Body weight gain $(\mathrm{kg})^{*}$ & $7.1 \pm 4.2$ & $7.1 \pm 5.3$ & 0.48 \\
\hline Weeks of delivery (weeks)* & $35.3 \pm 3.8$ & $38.0 \pm 2.1$ & 0.0007 \\
\hline \multicolumn{4}{|l|}{ Severity } \\
\hline h (h, ph, Ph) & $6(22.2 \%)$ & $33(44.0 \%)$ & 0.01 \\
\hline $\mathrm{H}(\mathrm{H}, \mathrm{pH}, \mathrm{PH})$ & $21(77.8 \%)$ & $42(56.0 \%)$ & 0.02 \\
\hline Fetal growth FGR (SD)* & $-1.4 \pm 1.7$ & $-0.7 \pm 1.5$ & 0.03 \\
\hline \multicolumn{4}{|l|}{ Methods of delivery } \\
\hline Caesarean section & $17(63.0 \%)$ & $36(48.0 \%)$ & 0.07 \\
\hline
\end{tabular}

*Data are average $( \pm \mathrm{SD})$.

For neonatal characteristics between the early- and late-onset PE groups, neonatal body weight at birth $(\mathrm{p}=$ 0.0008), neonatal height at birth $(\mathrm{p}=0.0002)$, neonatal BMI at birth $(\mathrm{p}=0.0005)$ were significantly lower and the frequency of SGA $(\mathrm{p}=0.004)$ was significantly higher in the early-onset group compared with the late-onset group (Table 3). 
Table 3. Comparison of neonatal characteristics between early- and late-onset preeclampsia.

\begin{tabular}{lccc}
\hline Variables & Early onset $(\mathrm{n}=27)$ & Late onset $(\mathrm{n}=75)$ & p value \\
\hline Body weight $(\mathrm{g})^{*}$ & $2050.9 \pm 921.1$ & $2586 \pm 663.9$ & 0.0008 \\
Height $(\mathrm{cm})^{*}$ & $44.1 \pm 5.7$ & $47.6 \pm 3.8$ & 0.0002 \\
BMI $\left(\mathrm{g} / \mathrm{cm}^{2}\right)^{*}$ & $9.9 \pm 2.3$ & $11.2 \pm 1.6$ & 0.0005 \\
SGA & $13(48.1 \%)$ & $19(25.3 \%)$ & 0.004 \\
\hline
\end{tabular}

*Data are average $( \pm S D)$.

Furthermore, the infant's body weight at 1 month after birth $(\mathrm{p}=0.003)$ and the infant's BMI at 1 month after birth $(p=0.03$ ) was significantly lower in the early-onset group than in the late-onset group. There was no significant difference in the infant's height at 1 month after birth between the groups. Mean daily weight gain during the neonatal period was significantly less in the early-onset group compared with the late-onset group (23.8 vs $30.1 \mathrm{~g} /$ day, $\mathrm{p}=0.049$ ), while the rate of weight gain during the neonatal period in the late-onset group was not significant but lower compared with the early-onset group (35.4\% vs 36.7\%), indicating a greater tendency for neonatal growth in early-onset than in late-onset cases (Table 4).

With regard to pathological findings in the placenta, placental weight in the early-onset group was significantly lower than that in the late-onset group ( 458.4 vs $524.0 \mathrm{~g}, \mathrm{p}=0.03$ ). Among the 47 patients who were subjected to histological diagnosis, pathological findings were observed in 10 of 16 (62.5\%) cases in the early-onset group, and were observed in 21 of 31 (67.7\%) cases in the late-onset group ( $=0.63$, Table 5).

\section{Discussion}

In this study, 102 cases of PE were divided into the groups of early- and late-onset PE, and compared in terms of perinatal progress and fetal development. We found no significant differences in the maternal physical state (maternal age, non-pregnant body weight, non-pregnant BMI, body weight at delivery, and weight gain during pregnancy) between these groups. However, there was less fetal development (the extent of FGR and frequency of SGA) in the early-onset groups than in the late-onset groups. Furthermore, neonatal body weight at birth, neonatal height at birth, and neonatal BMI at birth were significantly higher in late-onset cases than in earlyonset cases. In addition, the weight gain rate during the neonatal period in the early-onset group was higher than that in late-onset group.

In our study, we observed there were no significant differences of obesity and pathological findings in placenta between early- and late-onset groups although several reports demonstrated there were no different entities, placental factors and maternal metabolic condition [3]-[6]. In the cause of effects on fetal development, there was significantly high rate of severe PE in the early onset groups than in the late onset groups. Hauth et al. reported that in the cases of severe PE onset of FGR was 18.5\% and the mild PE was 10.2\% [15], and Buchbinder et al. reported that in women who have gestational hypertension or preeclampsia, rates of preterm delivery and delivery of small-for-gestational-age infants are increased only in severe hypertension [16] suggesting severity of PE is an important factor for fetal growth. In our study, early onset PE might have a greater effect than late onset PE on fetal development due to severity of PE.

The cause of asymmetrical type FGR is considered to be circulatory failure in the placenta, accompanied by fetal ischemia. Barker et al. reported a high level of incidence of obesity and lifestyle-related disease later in life among infants born with FGR [17]. Stettler et al. reported that the greater the weight gain in the 4 months after birth, the higher the risk of obesity later in life [18]. In our study, mean daily weight gain during the neonatal period was less in early-onset cases than in late-onset cases. However, despite this finding, the rate of weight gain during the neonatal period was higher in early-onset cases, with lower body weight at birth, BMI at birth, and extent of FGR than in late-onset cases. We only considered weight changes in the neonatal period, and as such, these are not sufficient indicators for evaluation of obesity and lifestyle-related disease later in life among infants born with FGR from mothers with PE. Further studies are necessary to investigate the rate of weight gain during the infancy period, along with the risk of future obesity and lifestyle-related disease in the offspring from early-onset preeclamptic patients.

In the current study, the early-onset group had a higher incidence of FGR and SGA than the late-onset group. 
Table 4. Comparison of the infant's characteristics at 1 month old between early- and late-onset preeclampsia.

\begin{tabular}{lccc}
\hline Variables & Early onset $(\mathrm{n}=25)$ & Late onset $(\mathrm{n}=52)$ & $\mathrm{p}$ value \\
\hline Body weight at one month after birth $(\mathrm{g})^{*}$ & $2751.6 \pm 1276.3$ & $3459.2 \pm 873.1$ & 0.003 \\
Height at one month after birth $(\mathrm{cm})^{*}$ & $50.3 \pm 4.8^{* *}$ & $51.4 \pm 4.4^{* * *}$ & 0.2 \\
BMI at one month after birth $\left(\mathrm{g} / \mathrm{cm}^{2}\right)^{*}$ & $12.7 \pm 2.5^{* *}$ & $13.8 \pm 1.5^{* * *}$ & 0.03 \\
Body weight gain $(\mathrm{g})^{*}$ & $716.6 \pm 465.7$ & $904.0 \pm 458.6$ & 0.049 \\
Body weight gain rate (\%) & 36.7 & 35.4 & 0.39 \\
\hline
\end{tabular}

*, Data are average $( \pm \mathrm{SD}), * *, \mathrm{n}=16 ; * * *, \mathrm{n}=38$.

Table 5. Comparison of characteristics of the placenta between early- and late-onset preeclampsia.

\begin{tabular}{lccc}
\hline Variables & Early onset $(\mathrm{n}=16)$ & Late onset $(\mathrm{n}=31)$ & $\mathrm{p}$ value \\
\hline Weight $(\mathrm{g})^{*}$ & $458.4 \pm 170.7$ & $524.0 \pm 144.4$ & 0.03 \\
Abnormal pathological findings** & $10 / 16(62.5 \%)$ & $21 / 31(67.7 \%)$ & 0.63 \\
\hline
\end{tabular}

*, Data are average $( \pm \mathrm{SD}) ; * *, \mathrm{n}=47$.

While neonates born to the early-onset group had a lower BMI at birth, their rate of weight gain was higher than that of those born in the late-onset group, suggesting that their rate of catch-up was faster. Although there were no significances of obesity and pathological findings in placenta between two groups, there were significant differences in fetal and neonatal growth according to the period of onset of PE. These findings suggest that the onset period might play important roles in fetal and neonatal growth. Further long follow up will be required to show whether the catch-up growth during neonatal period might affect the health later in life.

\section{References}

[1] Davey, D.A. and Mac Gillivary, I. (1988) The Classification and Definition of the Hypertensive Disorders of Pregnancy. American Journal of Obstetrics and Gynecology, 158, 892-898. http://dx.doi.org/10.1016/0002-9378(88)90090-7

[2] Brown, M.A., Lindheimer, M.D., de Swiet, M., van Assche, A. and Moutquin, J.M. (2001) The Classification and Diagnosis of the Hypertensive Disorders of Pregnancy: Statement from the International Society for the Study of Hypertension in Pregnancy (ISSHP). Hypertention in Pregnancy, 20, 9-14. http://dx.doi.org/10.3109/10641950109152635

[3] Sibai, B., Dekker, G. and Kupferminc, M. (2005) Pre-Eclampsia. Lancet, 365, 785-799. http://dx.doi.org/10.1016/S0140-6736(05)71003-5

[4] Aardema, M.W., Saro, M.C., Lander, M., de Wolf, B.T., Oosterhof, H. and Aarnoudse, J.G. (2004) Second Trimester Doppler Ultrasound Screening of the Uterine Arteries Differentiates between Subsequent Normal and Poor Outcomes of Hypertensive Pregnancy: Two Different Pathophysiological Entities? Clinical Science (London), 106, 377-382. http://dx.doi.org/10.1042/CS20030385

[5] Vatten, L.J. and Skjaerven, R. (2004) Is pre-Eclampsia More than One Disease? BJOG: An International Journal of Obstetrics and Gynaecology, 111, 298-302. http://dx.doi.org/10.1111/j.1471-0528.2004.00071.x

[6] Masuyama, H., Segawa, T., Sumida, Y., Masumoto, A., Inoue, S., Akahori, Y. and Hiramatsu, Y. (2010) Different Profiles of Circulating Angiogenic Factors and Adipocytokines between Early- and Late Onset Preeclampsia. BJOG: An International Journal of Obstetrics and Gynaecology, 117, 314-320. http://dx.doi.org/10.1111/j.1471-0528.2009.02453.x

[7] Masuyama, H., Nobumoto, E., Inoue, S. and Hiramatsu, Y. (2010) Potential Interaction of Brain Natriuretic Peptide with Hyperadiponectinemia in Preeclampsia. American Journal of Physiology, Endocrinology and Metabolism, 302, E687-E693. http://dx.doi.org/10.1152/ajpendo.00548.2011

[8] Watanabe, K., Naruse, K., Tanaka, K., Metoki, H. and Suzuki, Y. (2013) Outline of Definition and Classification of "Pregnancy induced Hypertension (PIH)". Hypertention Research in Pregnancy, 1, 3-4. http://dx.doi.org/10.14390/jsshp.1.3

[9] Shinozuka, N., Okai, T., Kohzuma, S., Mukubo, M., Shih, C.T., Maeda, T., Kuwabara, Y. and Mizuno, M. (1987) Formulas for Fetal Weight Estimation by Ultrasound Measurements Based on Neonatal Specific Gravities and Volumes. American Journal of Obstetrics and Gynecology, 157, 1140-1145. http://dx.doi.org/10.1016/S0002-9378(87)80278-8 
[10] Bonellie, S., Chalmers, J., Gray, R., Greer, I., Jarvis, S. and Williams, C. (2008) Centile Charts for Birthweight for Gestational Age for Scottish Singleton Births. BMC Pregnancy and Childbirth, 8, 5. http://dx.doi.org/10.1186/1471-2393-8-5

[11] Visser, G.H., Eilers, P.H., Elferink-Stinkens, P.M., Merkus, H.M. and Wit, J.M. (2009) New Dutch Reference Curves for Birthweight by Gestational Age. Early Human Development, 85, 737-744. http://dx.doi.org/10.1016/j.earlhumdev.2009.09.008

[12] Olsen, I.E., Groveman, S.A., Lawson, M.L., Clark, R.H. and Zemel, B.S. (2010) New Intrauterine Growth Curves Based on United States Data. Pediatrics, 125, e214-e224. http://dx.doi.org/10.1542/peds.2009-0913

[13] Cole, T.J. (1988) Fitting smoothed Centile Curves to Reference Data. Journal of the Royal Statistical Society, 151, 385-418. http://dx.doi.org/10.2307/2982992

[14] Benirschke, K. and Kaufmann, P. (2006) Pathology of the Human Placenta. 5th Edition, Springer-Verlag Berlin Heidelberg, New York, 155-157.

[15] Hauth, J.C., Ewell, M.G., Levine, R.J., Esterlitz, J.R., Sibai, B., Curet, L.B., Catalano, P.M. and Morris, C.D. (2000) Pregnancy Outcomes in Healthy Nulliparas Who Developed Hypertension. Calcium for Preeclampsia Prevention Study Group. Obstetrics and Gynecology, 95, 24-28. http://dx.doi.org/10.1016/S0029-7844(99)00462-7

[16] Buchbinder, A., Sibai, B.M. and Caritis, S. (2002) Adverse Perinatal Outcomes Are Significantly Higher In Severe Gestational Hypertension than in Mild Preeclampsia. American Journal of Obstetrics and Gynecology, 186, 66-71. http://dx.doi.org/10.1067/mob.2002.120080

[17] Godfrey, K.M. and Barker, D.J. (2000) Fetal Nutrition and Adult Disease. The American Journal of Clinical Nutrition, 71, 1344-1352.

[18] Stettler, N., Zemel, B.S., Kumanyika, S. and Stallings, V.A. (2002) Infant Weight Gain and Childhood Overweight Status in a Multicenter, Cohort Study. Pediatrics, 109, 194-199. http://dx.doi.org/10.1542/peds.109.2.194 